\title{
Oxo-centered carboxylate-bridged trinuclear complexes deposited on Au(111) by a mass-selective electrospray $\dagger \ddagger$
}

\author{
Valdis Corradini, ${ }^{* a}$ Christian Cervetti, ${ }^{a b}$ Alberto Ghirri, ${ }^{a}$ Roberto Biagi, ${ }^{a b}$ \\ Umberto del Pennino, ${ }^{a b}$ Grigore A. Timco, ${ }^{c}$ Richard E. P. Winpenny ${ }^{c}$ and \\ Marco Affronte ${ }^{a b}$
}

\author{
Received (in Montpellier, France) 28th January 2011, Accepted 26th May 2011 \\ DOI: $10.1039 / \mathrm{c} 1 \mathrm{nj} 20080 \mathrm{a}$
}

We explored the possibility to deposit Molecular NanoMagnets (metallorganic complexes) by electrospray. To this end, we developed an apparatus for nondestructive in vacuum deposition of fragile molecular complexes, by modifying a commercial Mass Spectrometer equipped with an electrospray ionization source. Starting from solution, this system creates a beam of ionized molecules which is then transferred into an evacuated region where molecules can be mass selected before deposition. To check the system efficiency, we deposited sub monolayers of oxo-centered carboxylate-bridged trinuclear complexes $\left(\mathrm{Cr}_{3}\right.$ and $\left.\mathrm{Cr}_{2} \mathrm{Ni}\right)$ on the $\mathrm{Au}(111)$ surface. By XPS and STM we determined the deposited molecule stoichiometry and the surface coverage. Results show that this type of apparatus works well for the in vacuum deposition of molecular nanomagnets and, thanks to the reduced dimensions, it is portable and adaptable to facilities requiring UHV.

\section{Introduction}

Molecular nanomagnets (MNM) have shown potentialities for applications, such as information technologies and in particular for magnetic data storage and processing. ${ }^{1-3}$ An important step in this direction is their deposition on suitable substrates in clean and controlled conditions. Differentdirect and indirect-strategies and methods have been developed in the last few years in order to obtain a submonolayer (sML) coverage of $\mathrm{MNM}^{4-9}$ while in depth investigations have shown that in some cases MNMs preserve their electronic and magnetic properties on the surface. ${ }^{10-13}$ Some fragile molecules deposited starting from the liquid phase, however, have shown some problems, like the detachment in solution of part of the organic ligands ${ }^{6,9}$ and, in some cases, the redox instability of the cluster core induced by the exposure to air. ${ }^{14,15}$ In addition, many powerful spectroscopic techniques require in-vacuum preparation of samples. Sublimation of powders could be an alternative way, but this

\footnotetext{
${ }^{a}$ Institute of Nanoscience-S3, CNR, via G. Campi 213/a 41125

Modena, Italy.E-mail: valdis.corradini@unimore.it

${ }^{b}$ Dipartimento di Fisica, Università di Modena e Reggio Emilia, via G. Campi 213/a 41125 Modena, Italy

${ }^{c}$ The Lewis Magnetism Laboratory, School of Chemistry,

The University of Manchester, Oxford Road, Manchester M139PL, UK

$\dagger$ This article is part of a themed issue on Molecular Materials: from Molecules to Materials, commissioned from the MolMat2010 conference. $\ddagger$ Electronic supplementary information available: STM images of the $\mathrm{Cr}_{3}$ and $\mathrm{Cr}_{2} \mathrm{Ni}$ deposited on the $\mathrm{Au}(111)$ surface by ESD/MS and by liquid phase. CCDC 803376. For ESI and crystallographic data in CIF or other electronic format see DOI: $10.1039 / \mathrm{c} 1 \mathrm{nj} 20080 \mathrm{a}$
}

approach requires heating at high temperature causing the degradation of thermolabile molecules.

Electrospray ionization (ESI) is a widely used technique in mass spectrometry ${ }^{16}$ to produce gas phase ions of large molecules (polymers, proteins, viruses) starting from solution. Several examples of surface coatings by ESI, like functional films, ${ }^{17}$ biological arrays ${ }^{18}$ and thin electrode production ${ }^{19}$ have been reported. Further works also reported on mass-selected deposition of organic molecules on different surfaces. ${ }^{20-26}$ Mass selection performed by means of a quadrupole analyzer allows to control the integrity of molecules and to assure the absence of contaminants, removing solvents and unwanted species. Yet, mass selection is not sufficient condition and a gentle deposition is also required in order to bring such molecules intact to the surface. Soft-landing ion beam deposition has been the topic of some studies. ${ }^{27,28}$ In these papers, for instance, it has been demonstrated that it is possible to bring nonvolatile compounds from a solution into the gas phase and to deposit them on a surface where they are present as molecular ion or as neutralized species by playing with their final kinetic energy. ${ }^{29}$

These features make ESI with Mass Selection an ideal tool for the deposition of fragile MNM on surfaces. In addition, working with the system parameters, it is possible to tune the molecule kinetic energy for the control of the film growth. Despite these capabilities, so far only few works have been devoted to develop and use ESI for in-vacuum deposition of MNM. ${ }^{30,31}$

Here we report on the high vacuum electrospray and mass selected deposition (ESD/MS) of antiferromagnetic Cr-based trimers on $\mathrm{Au}(111)$. The aim is to test the effectiveness of this 


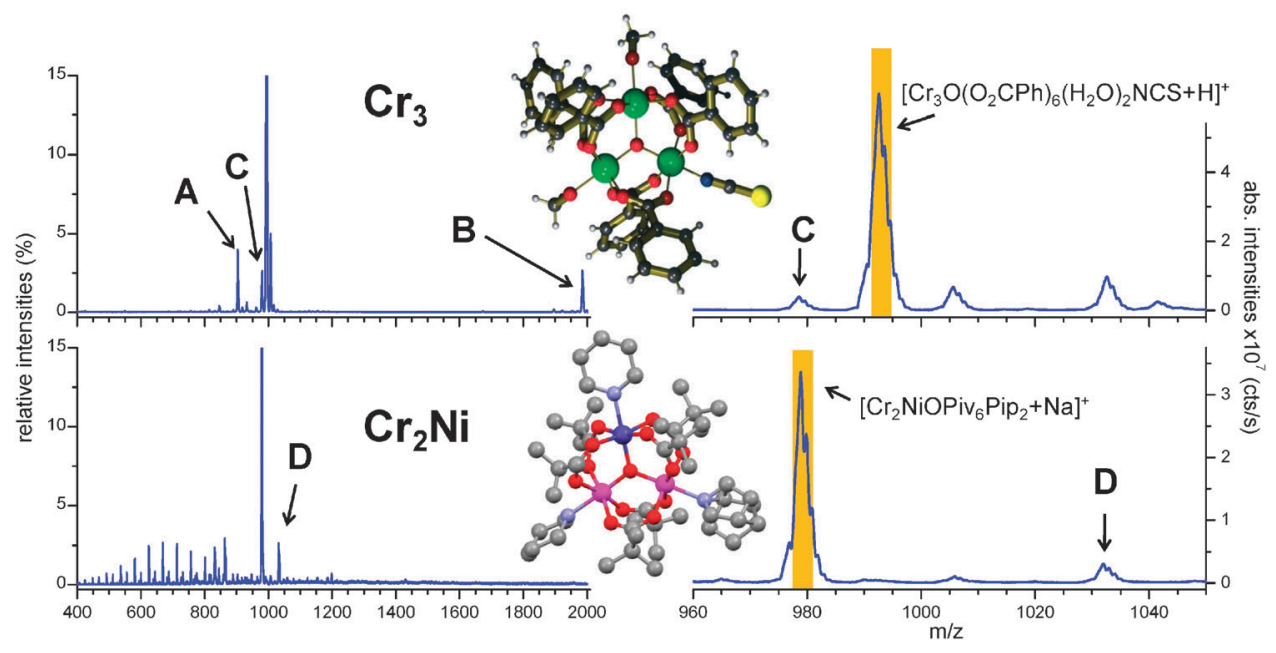

Fig. 1 Structures and corresponding positive-ion ESI mass spectra of $\mathrm{Cr}_{3}$ and $\mathrm{Cr}_{2} \mathrm{Ni}$ compounds, recorded in the 400-2000 $\mathrm{m} / z$ (left panels) and 960-1050 m/z (right panels) mass regions. ESD/MS parameters: concentration $=10 \mu \mathrm{M}$, speed of injection $=6 \mathrm{~mL} \mathrm{~h}^{-1}$, capillary (temperature $=$ $200{ }^{\circ} \mathrm{C}$, voltage $=2.5 \mathrm{KV}$ ), entrance cone $60 \mathrm{~V}$, exit cone $4.7 \mathrm{~V}$. The peak $\mathrm{A}=\left[\mathrm{Cr}_{3} \mathrm{O}\left(\mathrm{O}_{2} \mathrm{CPh}\right)_{6}\right]^{+}, \mathrm{B}=\left[\mathrm{Cr}{ }_{3} \mathrm{O}\left(\mathrm{O}_{2} \mathrm{CPh}\right)_{6}\right]_{2}(\mathrm{NCS})(\mathrm{MeOH})_{4}$, $\mathrm{C}=\left[\mathrm{Cr}_{3} \mathrm{O}\left(\mathrm{O}_{2} \mathrm{CPh}\right)_{6} \mathrm{NCS}+\mathrm{Na}\right]^{+}, \mathrm{D}=\left[\mathrm{Cr}_{3} \mathrm{OPiv}_{6} \mathrm{Pip}_{3}\right]^{+}$. The highlighted regions around the desired mass peaks $\left(992.5 \mathrm{~m} / z\right.$ for $\mathrm{Cr}_{3}$ and $979.2 \mathrm{~m} / \mathrm{z}$ for $\mathrm{Cr}_{2} \mathrm{Ni}$ ) represent the allowed mass ranges during the ESD-MF deposition (see discussion in the text).

procedure in the case of such fragile MNM. We used combined XPS and STM analysis to verify how far the ESD/MS process preserves the chemical and structural integrity of the deposited molecules. Among MNM, the class of antiferromagnetic (AF) spin rings has recently acquired interest since they are nice "clean" examples of quantum antiferromagnets with features suitable for quantum information processing. ${ }^{32-34}$ The simplest model system of AF rings are trimers with three magnetic ions in a triangular arrangement. For such systems, phenomena like spin frustration, spin chirality, decoherence and thermal relaxation have been investigated in the past ${ }^{35-37}$ and they now attract a renewed interest in new contexts. Isosceles AF spin triangles, like $\mathrm{Cr}_{2} \mathrm{Cu}$, have been recently proposed as units for moleculebased quantum gates, ${ }^{38}$ while spin manipulation by electric fields was recently proposed for AF spin triangles like $\mathrm{Cr}_{3}{ }^{39}$ We recently used $\mathrm{Cr}_{2} \mathrm{Cu}$ trimers as simple prototype of molecular clusters to probe the local magnetization. ${ }^{40}$

\section{Experimental details}

Unless stated otherwise, all reagents and solvents were purchased from Aldrich and used without further purification. $\left[\mathrm{Cr}_{2} \mathrm{NiO}\left(\mathrm{O}_{2} \mathrm{CCMe}_{3}\right)_{6}\left(\mathrm{HNC}_{5} \mathrm{H}_{10}\right)_{3}\right]$, where $\mathrm{HNC}_{5} \mathrm{H}_{10}$ is piperidine, and $\left[\mathrm{Cr}_{3} \mathrm{O}\left(\mathrm{O}_{2} \mathrm{CPh}\right)_{6}\left(\mathrm{H}_{2} \mathrm{O}\right)_{3}\right] \mathrm{ClO}_{4} \cdot 2 \mathrm{H}_{2} \mathrm{O}$ were synthesized as described in ref. 41.

\subsection{Synthesis of $\left[\mathrm{Cr}_{3} \mathrm{O}\left(\mathrm{O}_{2} \mathrm{CPh}\right)_{6}(\mathrm{NCS})(\mathrm{HOMe})_{2}\right]$}

$\left[\mathrm{Cr}_{3} \mathrm{O}\left(\mathrm{O}_{2} \mathrm{CPh}\right)_{6}\left(\mathrm{H}_{2} \mathrm{O}\right)_{3}\right] \mathrm{ClO}_{4} \cdot 2 \mathrm{H}_{2} \mathrm{O}(0.5 \mathrm{~g}, 0.46 \mathrm{mmol})$, was dissolved in $50 \mathrm{ml}$ of methanol with stirring and gentle heating. To this solution potassium thiocyanate $(\mathrm{KSCN})(0.2 \mathrm{~g}, 2.06 \mathrm{mmol})$ was added and the solution was stirred and refluxed for $5 \mathrm{~min}$ then filtered. The filtrate was allowed to cool to room temperature and left for slow evaporation of the solvent. After one week a green microcrystalline product including quality crystals for X-ray crystallographic analysis was collected by filtration and washed with methanol. Yield: $0.36 \mathrm{~g}(77 \%)$. Elemental analysis calcd (\%) for $\mathrm{C}_{45} \mathrm{H}_{38} \mathrm{Cr}_{3} \mathrm{~N}_{1} \mathrm{O}_{15} \mathrm{~S}_{1}$ : Cr 15.28,
C 52.95, H 3.75, N 1.37, S 3.14; found: Cr 15.11, C 52.82, H 3.33, N 1.28, S 2.83.

Crystal data: $\mathrm{C}_{46} \mathrm{H}_{45} \mathrm{Cr}_{3} \mathrm{~N}_{1} \mathrm{O}_{18} \mathrm{~S}_{1}, M=1087.91$, monoclinic, $a=11.2760(14) \AA, b=21.607(3) \AA, c=21.504(3) \AA, \alpha=90^{\circ}$, $\beta=93.4060(10)^{\circ}, \gamma=90^{\circ}, V=5230.0(12) \AA^{3}, T=100(2) \mathrm{K}$, space group $P 121 / c 1, Z=4,39991$ reflections measured, 27801 independent reflections $\left(R_{\mathrm{int}}=0.0784\right)$. The final $R_{1}$ values were $0.1287(I>2 \sigma(I))$. The final $w R\left(F^{2}\right)$ values were $0.2788(I>2 \sigma(I))$. The final $R_{1}$ values were 0.1566 (all data). The final $w R\left(F^{2}\right)$ values were 0.2899 (all data). CCDC 803376. Crystallographic structures of $\mathrm{Cr}_{3}$ and $\mathrm{Cr}_{2} \mathrm{Ni}$ are shown in Fig. 1. The metallic ions are placed at the vertexes of a triangle. Their chemical bridging occurs by means of the central oxygen and two carboxylate bridges that provide antiferromagnetic (AF) superexchange coupling between the metal centres. The local symmetry of each chromium or nickel atom is represented by a slightly distorted octahedron $\left(O_{h}\right)$ with six apical $\mathrm{O}$ atoms or five $\mathrm{O}$ and one $\mathrm{N}$ atoms equidistant from the metal ion.

\subsection{Portable deposition system}

The commercial Thermo Finnigan Surveyor Mass Spectrometer quadrupole (MSQ) consists in an Electro Spray Ionization source in air and transfer lenses, pre-filter, quadrupole mass analyzer and ion detection system all enclosed in a vacuum vessel. With a proper modification of this instrument, we developed an ESD/MS apparatus for the in vacuum deposition of thermolabile nanoclusters which allow the selection of the desired mass-to-charge ratio. The reduced dimensions of this system make it easy to transport to other laboratories or large scale facilities.

In Fig. 2 a sketch of the ESD/MS apparatus and operation are shown. Schematically:

(i) The sample solution enters the capillary, which is kept at high voltage, producing ions of the same sign of its voltage.

(ii) The capillary sprays the solution into a fine mist of droplets that are electrically charged at their surface which 


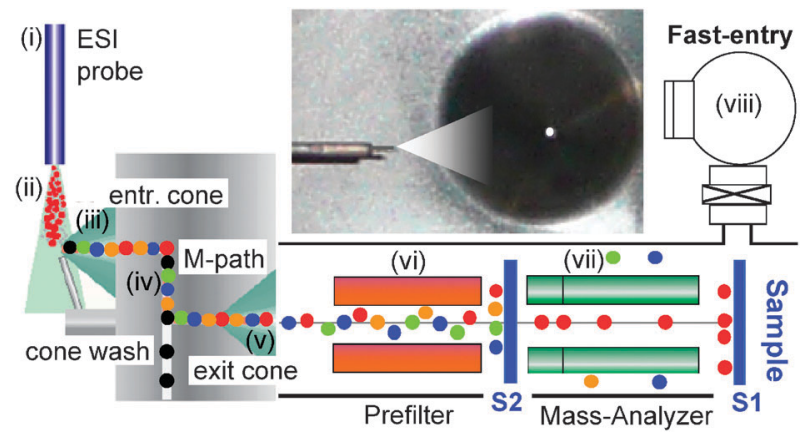

Fig. 2 Schematic of the ESD/MS apparatus. The sample surface can be positioned at the exit of the mass-filter (pos. S1) or after the prefilter (pos. S2). All the parts with numbers are discussed in the text.

explode into smaller droplets because of the Coulomb repulsion. ${ }^{42,43}$

(iii) The entrance cone and the low vacuum produced by the forepump in the first stage of the spectrometer draws inside it both ionized and neutral molecules.

(iv) In the M-path region, the fore pump draws the neutral molecules out of the vessel while the ionized molecules are extracted by the exit cone potential and sent to the prefilter.

(vi) The RF/dc prefilter focuses the ions on the entrance slit of the quadrupole mass analyzer.

(vii) The mass analyzer separates the ions according to their mass-to-charge ratio. Its mass range is 17-2000 amu with a mass resolving power $(m / \Delta m) \approx 1000$. In the analysis mode the selected ions are then collected by the detection system which includes a $10 \mathrm{kV}$ conversion dynode and an off-axis electron multiplier. Before the ESI mass spectra investigation, we have performed a mass-scale calibration with the proper calibrant, of the whole MSQ apparatus.

For the direct deposition on a surface, we have properly modified the vacuum chamber of the Surveyor MSQ and connected it, through a gate valve, to a transferable minichamber (viii) equipped with a pumping system and a manipulator by which a small sample can be inserted in the narrow space between the quadrupole exit and the conversion dynode. In turn from the mini chamber a transfer unit isolated by a second gate valve can be separated.

Prior to deposition all the parameters of the ESD/MS process (dose, ionization temperatures and acceleration voltages) can be optimized and then the required mass range selected (see the highlighted region in Fig. 1) by fixing an interval around the desired mass peak. The deposition is then obtained by positioning the clean $\mathrm{Au}(111)$ surface directly in front of the exit of the quadrupole mass-analyzer (position S1) in high vacuum $\left(5 \times 10^{7} \mathrm{mbar}\right)$ conditions. If we want to deposit all the masses present in the solution, without selection, the substrate can be positioned at the exit of the prefilter (PF) in position S2. After the deposition, the mini-chamber can be separated and connected with any other UHV experimental stations for the analysis, without breaking the vacuum. For STM measurements instead the sample was, for problems of size, exposed to air and then mounted on the STM sample holder. The Au(111) surface was cleaned by repeated cycles of $\mathrm{Ar}+$ sputtering-annealing at $730 \mathrm{~K}$ in UHV conditions until a sharp $(22 \times \sqrt{ } 3)$ LEED pattern is obtained, prior to the transfer into the ESD/MS system. The sample preparation devoted to XPS analysis showed a residual carbon contamination, probably due to a malfunction of the ion gun. It was however very small, in the range of hundredths of ML, and has been subtracted to the spectra discussed in the following.

\section{Results and discussion}

\subsection{Choice of ESD/MS parameters}

As a first step, we optimized the parameters for ionization and deposition of the oxo-centered carboxylate-bridged trinuclear complexes: $\mathrm{Cr}_{3} \mathrm{O}\left(\mathrm{O}_{2} \mathrm{CPh}\right)_{6}\left(\mathrm{H}_{2} \mathrm{O}\right)_{2} \mathrm{NCS}\left(\mathrm{Cr}_{3}\right.$ in short) and $\mathrm{Cr}_{2} \mathrm{NiO} \mathrm{Piv}_{6} \mathrm{Pip}_{3}\left(\mathrm{Cr}_{2} \mathrm{Ni}\right.$ in short $) .{ }^{44}$ Palii et $a l .{ }^{44}$ observed that, during ESI Mass Spectra (ESI-MS) measurements, the qualitative and quantitative yields of ions depend, to a large extent, on the chemical species introduced into the mass spectrometer as well as on the ESI parameters: capillary voltage, skimmer voltage, capillary temperature and pressure in the external ESI source. In our case, the ESD/MS parameters that can be properly tuned are: concentration of the solution, injection speed, temperature $\left(0-500{ }^{\circ} \mathrm{C}\right)$ and voltage $(0-5 \mathrm{KV})$ of the ESI capillary, entrance cone voltage $(0-200 \mathrm{~V})$ and allowed mass range. $\left[\mathrm{M}_{3} \mathrm{O}\left(\mathrm{O}_{2} \mathrm{CR}\right)_{6} \mathrm{~L}_{3}\right] \mathrm{X}$ trimers are labile in solution, in particular for what concerns the ligands (L) in the apical positions (see ref. 44 and references therein). Therefore we have extensively studied the solubility, the ionizability, the chemical stability of $\mathrm{Cr}_{3}$ and $\mathrm{Cr}_{2} \mathrm{Ni}$ derivatives as a function of solvent, dose, ionization temperatures, applied voltages (at the capillary and at the entrance cone), and charge status of the molecules.

For both derivatives, the largest yields were reached with a $10 \mu \mathrm{M}$ concentration and an injection speed of $6 \mathrm{~mL} \mathrm{~h}^{-1}$. Below these values the yield strongly decreases while, above that, occlusion of the capillary occurred. The solvent used is 90\% methanol and 10\% tetrahydrofuran (dichloromethane) for $\mathrm{Cr}_{3}\left(\mathrm{Cr}_{2} \mathrm{Ni}\right)$. Concerning the ionization temperature, the best conditions were reached by heating the ESI capillary between $200{ }^{\circ} \mathrm{C}$ and $350{ }^{\circ} \mathrm{C}$. Below $150{ }^{\circ} \mathrm{C}$ we found problems with capillary occlusion and strongly decreased rate, while above $400{ }^{\circ} \mathrm{C}$ cluster dissociation occurs. For the acceleration voltages we choose $2.5 \mathrm{KV}$ for the ESI capillary and $60 \mathrm{~V}$ for the entrance cone. The integrity of the deposited molecules also depends on their kinetic energy when impinging on the surface. In fact the landing kinetic energy must be low enough to avoid the molecule cracking or disruption. In our case this energy, which is controlled by the exit cone potential, was set at $4.7 \mathrm{eV}$ per charge, a value that is considered within the range of soft landing regime for fragile organic ions. ${ }^{22,45}$

In these conditions we obtained an ion flux of $6 \times 10^{7}$ ions s ${ }^{-1}$ for $\mathrm{Cr}_{3}$ and $3.5 \times 10^{7}$ ions $\mathrm{s}^{-1}$ for $\mathrm{Cr}_{2} \mathrm{Ni}$ (see right panels of Fig. 1), corresponding to an ion current of about $10 \mathrm{pA}$ for $\mathrm{Cr}_{3}$ and $6 \mathrm{pA}$ for $\mathrm{Cr}_{2} \mathrm{Ni}$ in good agreement with values present in the literature. ${ }^{25}$ If we consider a speed injection of $6 \mathrm{~mL} \mathrm{~h}^{-1}$, the maximum volume deposited $(50 \mathrm{~mL})$ corresponds to a total dose of $80 \mathrm{pAh}$ for $\mathrm{Cr}_{3}$ and $50 \mathrm{pAh}$ for $\mathrm{Cr}_{2} \mathrm{Ni}$.

\subsection{Positive-ion ESI mass spectra}

In Fig. 1, the structures of $\mathrm{Cr}_{3}$ and $\mathrm{Cr}_{2} \mathrm{Ni}$ are shown together with the corresponding positive-ion ESI-MS spectra, after the 
optimization of the ESD/MS parameters and recorded in the 400-2000 $\mathrm{m} / \mathrm{z}$ (left panels) and 960-1050 $\mathrm{m} / \mathrm{z}$ (right panels) mass regions. Since $\mathrm{Cr}_{3}$ and $\mathrm{Cr}_{2} \mathrm{Ni}$ are neutral molecules, for the ESI process, they must be properly pre-ionized. From the ESI-MS spectra of the $\mathrm{Cr}_{3}$ derivative (see ref. 44 for details on the assignment of the different peaks), the most intense peak at $992.5 \mathrm{~m} / \mathrm{z}$ corresponds to the expected $\left[\mathrm{Cr}_{3} \mathrm{O}\left(\mathrm{O}_{2} \mathrm{CPh}\right)_{6^{-}}\right.$ $\left.\left(\mathrm{H}_{2} \mathrm{O}\right)_{2} \mathrm{NCS}+\mathrm{H}\right]^{+}$while the peak at about 980 is associated to $\left[\mathrm{Cr}_{3} \mathrm{O}\left(\mathrm{O}_{2} \mathrm{CPh}\right)_{6} \mathrm{NCS}+\mathrm{Na}\right]^{+}$. The second peak in intensity (about $4 \%$ of the main one) at $m / z=898$ can be ascribed to $\left[\mathrm{Cr}_{3} \mathrm{O}\left(\mathrm{O}_{2} \mathrm{CPh}\right)_{6}\right]^{+}$, where the NCS unit and two water molecules have left the triangle. A peak detected at $1986 \mathrm{~m} / z$, which is about the double of the main peak mass, has been assigned to the supramolecular assembly $\left[\mathrm{Cr}_{3} \mathrm{O}\left(\mathrm{O}_{2} \mathrm{CPh}\right)_{6}(\mathrm{MeOH})_{2}\right]_{2}(\mathrm{NCS})$.

For what concerns $\mathrm{Cr}_{2} \mathrm{Ni}$, we find the main peak at $979.2 \mathrm{~m} / \mathrm{z}$, slightly lower than the expected molecular peak at about $m / z=$ 1039. The $979.2 \mathrm{~m} / z$ peak is likely due to the ion $\left[\mathrm{Cr}_{2} \mathrm{NiO} \mathrm{Piv}_{6}\right.$ $\left.\mathrm{Pip}_{2}+\mathrm{Na}\right]^{+}$. This is a typical situation for the ionization of neutral molecules in ESI-MS processes. ${ }^{44}$ In fact since the $\mathrm{Cr}_{2} \mathrm{NiOPiv}_{6} \mathrm{Pip}_{3}$ is a neutral molecule, if one Pip $\left(\mathrm{C}_{5} \mathrm{H}_{11} \mathrm{~N}\right.$, neutral) is lost, then one $\mathrm{Na}^{+}$ion, coming from the solvent, can coordinate to the oxygen of the carboxylate, leading to the positive single charge of the resulting molecule. The less intense peak at $m / z=1032$ might be the cation $\left[\mathrm{Cr}_{3} \mathrm{OPiv}_{6} \mathrm{Pip}_{3}\right]^{+}$.

To start the deposition, we first selected the allowed mass ranges (see the highlighted region in Fig. 1) by fixing an interval of $\pm 1 \mathrm{~m} / \mathrm{z}$ around the desired mass peak of $992.5 \mathrm{~m} / \mathrm{z}$ for $\mathrm{Cr}_{3}$ and $979.2 \mathrm{~m} / \mathrm{z}$ for $\mathrm{Cr}_{2} \mathrm{Ni}$ and then we positioned the clean $\mathrm{Au}(111)$ surface directly in front of the exit of the quadrupole mass-analyzer (position S1 in Fig. 2). In this way, all the species with mass out of the selected range are cut out by the filter. The effectiveness of the mass filtering (MF) can be checked by comparing the films obtained with MF (sample in S1 position, ESD-MF mode) with those without MF (sample at the exit of the prefilter in position S2, ESD-PF mode).

\subsection{STM results}

We first investigated the deposition by $\mathrm{ESD} / \mathrm{MS}$ of $\mathrm{Cr}_{3}$ (see Fig. 3) and $\mathrm{Cr}_{2} \mathrm{Ni}$ molecules (see $\mathrm{ESI} \ddagger$ ) on $\mathrm{Au}(111)$ under different methods/conditions by means of STM. Panel (a) shows the typical "herringbone" reconstruction of clean Au(111) surface prior to deposition. As stated above the $\mathrm{Au}(111)$ surface was cleaned by repeated cycles of $\mathrm{Ar}+$ sputtering-annealing at $730 \mathrm{~K}$ in UHV conditions until a sharp $(22 \times \sqrt{ } 3)$ LEED pattern was obtained. Panel (b) shows the STM image relative to the films deposited by using only the pre-filtering (ESD-PF mode). The surface shows the presence of large two dimensional "islands" in which we can identify the bright spots, representing the isolated molecules, always surrounded by lower structures (height $<0.5 \mathrm{~nm}$ ) probably due to the fragmentation of organic ligands in the ionization process. Conversely, in the STM image of the mass-filtered (ESD-MF mode) deposition, shown in panel (c), we observe a quite homogeneous distribution of isolated clusters on the surface, while the small entities (height $<0.2 \mathrm{~nm}$ and diameter $<1 \mathrm{~nm}$ ) are very likely a contamination since the sample was exposed to air before being mounted on the STM sample holder (see Experimental details). This hypothesis is supported by measurements made on samples solely exposed to air.

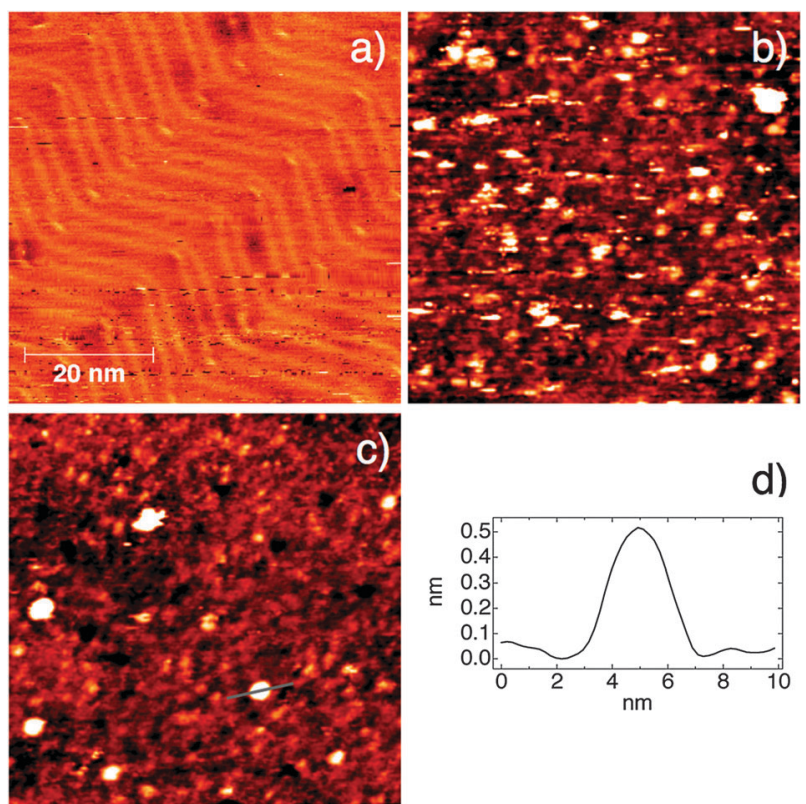

Fig. 3 STM images of: (a) reconstructed $\mathrm{Au}(111)$ surface prior to deposition; (b) pre-filtered $(5 \mathrm{ml})$, and (c) mass-filtered $(50 \mathrm{ml})$ depositions by $\mathrm{ESD} / \mathrm{MS}$ of $\mathrm{Cr}_{3}$ molecules on gold. (d) Line profile. For all images the tunneling current was $30 \mathrm{pA}$ and the bias voltage $2 \mathrm{~V}$.

The direct comparison between panels (b) and (c) makes clear that the surfaces where the molecules have been deposited using the ESD-MF method have more uniform particle sizes (i.e. bright spots appearing on the surfaces) than the surfaces modified with the ESD-PF method. STM images of films obtained by depositions from liquid-phase (see ESI $\ddagger$ ) show clusters whose shape is comparable with those ESD/MS deposited indicating that the molecular integrity is preserved.

Line profiles (panel (d)) taken on the large entities in Fig. 3c show a full-width half-maximum of about $2.8 \pm 0.5 \mathrm{~nm}$, in agreement with the expected diameter of the clusters $(1.5 \mathrm{~nm})$ convoluted with the not negligible curvature radius of the tip. The average apparent-height of the molecules $(0.5 \pm 0.1 \mathrm{~nm})$ is somehow lower than the expected dimension $(1.5 \mathrm{~nm})$ but this is probably due to a lower local density of states associated with the molecules as compared with the metallic Au surface.

From a statistical analysis of the STM images, for the ESD-PF mode $(5 \mathrm{ml})$ and the ESD-MF mode $(50 \mathrm{ml})$, we derived a denser packing of the $\mathrm{Cr}_{3} \mathrm{ML}$, with respect to $\mathrm{Cr}_{2} \mathrm{Ni}$. In fact for $\mathrm{Cr}_{3}$ we found a coverage of about $20-40 \%$ (0-20\%) for the ESD-PF (ESD-MF) deposition and of 5-25\% $(0-15 \%)$ for the ESD-PF (ESD-MF) deposited $\mathrm{Cr}_{2} \mathrm{Ni}$. The fact that clusters can be easily moved by the scanning tip, also at the lowest tunneling currents $(30 \mathrm{pA})$, indicates that the trimers are not well immobilized on the gold surface. For this reason the coverage obtained by STM slightly underestimates values derived by XPS.

\subsection{XPS results}

The STM results are confirmed by quantitative XPS analysis. In Fig. 4 the core levels of $\mathrm{Cr}_{2} \mathrm{Ni}$ and $\mathrm{Cr}_{3}$ deposited on $\mathrm{Au}(111)$ with MF (ESD-MF mode) or without (ESD-PF mode) are reported. Core level intensities have been normalized 
accounting for the atomic sensitivity and electronic signal attenuation. The $\mathrm{Cr}-2 \mathrm{p}, \mathrm{Ni}-2 \mathrm{p}, \mathrm{C}-1 \mathrm{~s}$ and $\mathrm{N}-1 \mathrm{~s}$ core level line-shapes measured for the ESD MLs fit well with the corresponding data obtained for a multilayer deposited by liquid phase.

For $\mathrm{Cr}_{2} \mathrm{Ni}$, with or without $\mathrm{MF}$, the measured ratios $\mathrm{Cr} / \mathrm{Ni}=$ $2 \pm 0.2$ and $\mathrm{Cr} / \mathrm{O}=14 \pm 3$ well agree with the expected values, indicating that the ESD/MS process preserves the stoichiometry of the trimer cores $(\mathrm{Cr}, \mathrm{Ni}, \mathrm{O})$. In the $\mathrm{C}-1$ s core level spectra two components are evident: $\mathrm{C} 1$ at $284.5 \mathrm{eV}$
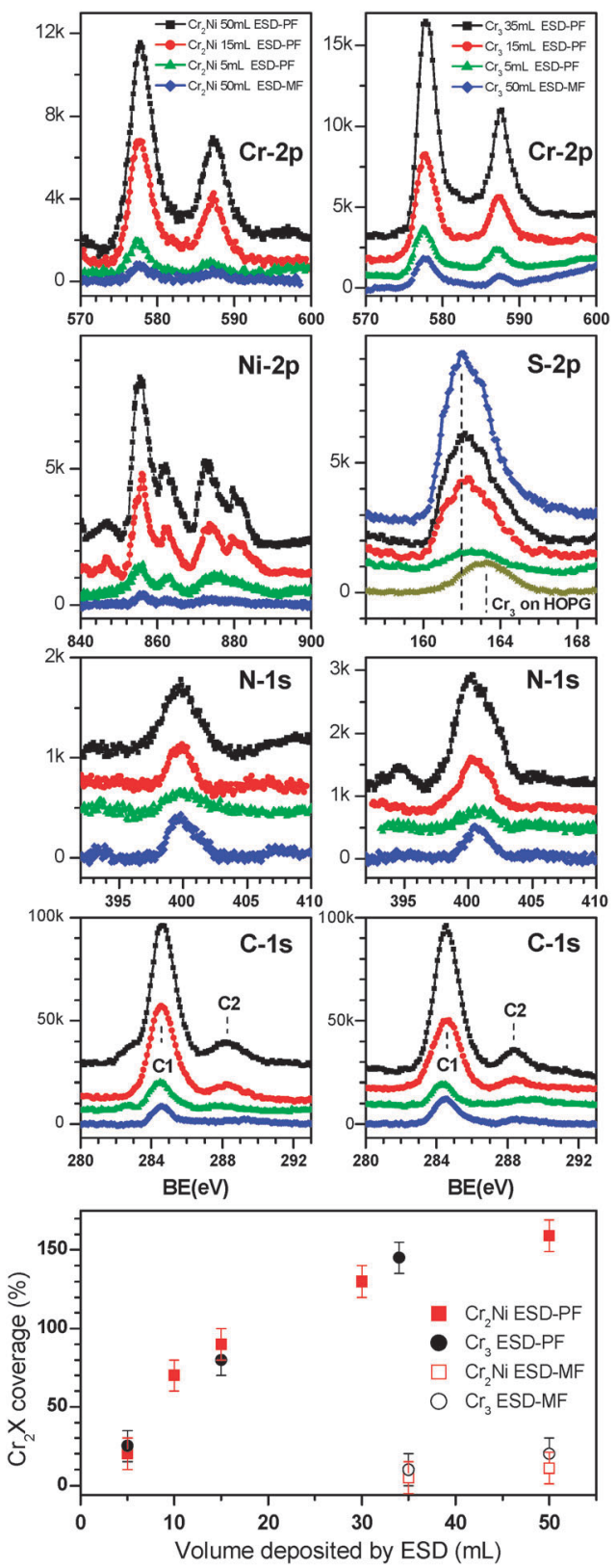

Fig. 4 Core levels of the $\mathrm{Cr}_{2} \mathrm{Ni}$ (left panel) and $\mathrm{Cr}_{3}$ (right panel) deposited on $\mathrm{Au}(111)$ with ESD-PF and ESD-MF modes. The background contribution has been subtracted. The S-2p core levels, measured for a thick film of $\mathrm{Cr}_{3}$ on HOPG were also reported as a reference. In the bottom panel, the values of coverage, derived from the Au-4f/Cr-2p ratio, for the ESI deposited $\mathrm{Cr}_{2} \mathrm{Ni}$ and $\mathrm{Cr}_{3}$ with $\mathrm{MF}$ (open symbols) and without MF (filled symbols) are reported. (typical of hydrocarbons) and $\mathrm{C} 2$ at $288.4 \mathrm{eV}$ (assigned to the carboxylate). In the $\mathrm{Cr}_{2} \mathrm{Ni}$ molecule there are 6 carbon in the carboxylates and 39 in Pip and methyl groups. The fact that the component $\mathrm{C} 1$ is $8 \pm 2$ times higher than $\mathrm{C} 2$ (in fair agreement with the expected ratio of $39 / 6=6.5$ ) indicate that not only the stoichiometry is preserved but that also the carboxylate bridges are unaffected. Conversely, looking at the $\mathrm{N} / 2 \mathrm{Cr}$ ratio we find that without $\mathrm{MF}$ this ratio is lower than expected ( 1 instead of 3 ) indicating a nitrogen deficit while with MF the stoichiometry is maintained. The presence of the Na-1s core level (spectra not shown) unambiguously confirms what already inferred by the ESI-MS spectra, that is in $\mathrm{Cr}_{2} \mathrm{NiOPiv}_{6} \mathrm{Pip}_{3}$ one Pip unit is lost and one $\mathrm{Na}^{+}$ion is absorbed on the neutral molecule charging it.

For what concern $\mathrm{Cr}_{3}$, the ratio $\mathrm{Cr} / \mathrm{O}=18 \pm 5$ agrees with the expected value of 15 . In the $\mathrm{Cr}_{3}$ molecule there are $6 \mathrm{C}$ in the carboxylates and 37 in other sites ( $\mathrm{Ph}$ and NCS groups). The fact that the component $\mathrm{C} 1$ is $7 \pm 2$ times higher than $\mathrm{C} 2$ (expected ratio $37 / 6=6$ ) indicates that also in this case the carboxylate bridges are maintained. Thus, also for $\mathrm{Cr}_{3}$, the $\mathrm{ESD} / \mathrm{MS}$ process preserves the stoichiometry of the core, though in this case the situation is complicated by the presence of a weakly bonded thiocyanate ligand $(\mathrm{N}-\mathrm{C}-\mathrm{S})$. What we observe is that, without $\mathrm{MF}$ the $\mathrm{S} / 3 \mathrm{Cr}$ ratio is $4 \pm 2$ instead of 1 clearly indicating a significant excess of sulfur. This tendency is enhanced with MF where the S-2p intensity suggests the formation of a S-containing sub-ML on the Au(111) surface. If we analyze the energy position of the $S-2 p$ core levels (see Fig. 4), measured for a $\mathrm{Cr}_{3}$ thick film on $\mathrm{HOPG}$, we find the expected peak at about $163 \mathrm{eV}$ which can be easily assigned to unbound S atoms ${ }^{46,47}$ (namely N-C-S ligands with unbound S). Conversely, in the ESD MLs, the presence of the main component at $162 \mathrm{eV}$, assigned to $\mathrm{S}$ atoms bonded to gold, ${ }^{46,47}$ is evident. A possible explanation is that the kinetic energy of the molecule reaching the surface and the strong affinity between sulfur and gold increase the tendency of the $\mathrm{N}-\mathrm{C}-\mathrm{S}$ ligand to decompose, leading to the formation of a S-containing sub-ML on the Au(111) surface. This behavior has been already observed in other systems deposited from the liquid phase. ${ }^{6,9,12}$ Starting from the $\mathrm{Au} / \mathrm{Cr}$ ratio and taking into account the gold signal attenuation due to the overlayer, we can calculate the average area occupied by each cluster. Assuming that a complete coverage is made by molecules lying flat on the surface and assigning to each molecule an area of $1.8 \mathrm{~nm}^{2}$, we derived the coverages reported in the bottom panel of Fig. 4, which are in good agreement with the values estimated by STM.

From Fig. 4 we infer that the cluster deposition rate in the $\mathrm{ESD} / \mathrm{MS}$ process does not significantly depend on the cluster nature $\left(\mathrm{Cr}_{2} \mathrm{Ni}\right.$ or $\left.\mathrm{Cr}_{3}\right)$. To get a complete $\mathrm{ML}$ without $\mathrm{MF}$ (filled symbols), that is by collecting all masses, $20 \mathrm{~mL}$ of solution are needed, whereas with MF (open symbols) about $200-250 \mathrm{~mL}$ are required. Since the injection speed is $6 \mathrm{~mL} \mathrm{~h}^{-1}$, the deposition rate without the mass filter is about 0.3 ML per hour, while selecting only the desired mass the deposition rate drops to $0.03 \mathrm{ML}$ per hour. Considering that the molecule flux in the capillary is $10^{13} \mathrm{molec} \mathrm{s}^{-1}$ (concentration $10 \mu \mathrm{M})$ and that about $5 \times 10^{11} \mathrm{molec}^{-2}$ are necessary to complete a ML, the yield of the whole ESD/MS process is about 
$1 / 10^{5}\left(1 / 10^{6}\right)$ without MF (with MF), i.e. only one each $10^{5}\left(10^{6}\right)$ molecules present in the solution is deposited on the surface.

\section{Conclusions}

We have realized a compact and portable deposition system exploiting an Electro-Spray Ionization source and an (optional) mass selection, for the deposition of thermolabile molecules in High Vacuum. With this apparatus we successfully deposited $\mathrm{Cr}_{3}$ and $\mathrm{Cr}_{2} \mathrm{Ni}$ molecular antiferromagnetic trimers on gold surface. Combined ESI-MS, STM and XPS analysis ssentially show chemical and structural integrity of these fragile molecules after deposition. The ionization process of originally neutral molecules necessary for their transport and mass selection can lead to small changes in the external cage of the clusters yet, we checked that this occurs without substantial alteration of their cores. We expect, therefore, that the relevant magnetic properties of the clusters which justify the wide interest in them, remain unchanged after deposition. Preliminary XAS and X-ray Circular Magnetic Dichroism experiments at a synchrotron radiation source which make use of the ESI set up described in this work are in progress and they will better clarify these aspects. In summary, we believe that this deposition technique represents an important step ahead with respect to liquid phase deposition, since dissolved contaminants and molecule moieties can be avoided. The cleanliness of the deposition process is further enhanced because the whole procedure can be entirely made in vacuum.

\section{Acknowledgements}

This work was partially funded by SEED project-INFM in 2008 and European STREP project MolSpinQIP (Molecular Spin Clusters for Quantum Information Processing), contract No. 211284.

We thank Alberto Magnani of the University of Modena and Reggio Emilia for the realization of the mechanical modifications of the ESI vacuum chamber.

We acknowledge Dr Robin Pritchard for solving the crystal structure of the compuund $\left[\mathrm{Cr}_{3} \mathrm{O}\left(\mathrm{O}_{2} \mathrm{CPh}\right)_{6}(\mathrm{NCS})(\mathrm{HOMe})_{2}\right]$.

\section{References}

1 C. Joachim, J. K. Gimzewski and A. Aviram, Nature, 2000, 408, 541.

2 A. Caneschi, D. Gatteschi, R. Sessoli, A. L. Barra, L. C. Brunel and M. Guillot, J. Am. Chem. Soc., 1991, 113, 5873; R. Sessoli, H. L. Tsai, A. R. Schake, S. Y. Wang, J. B. Vincent, K. Folting, D. Gatteschi, G. Christou and D. N. Hendrickson, J. Am. Chem. Soc., 1993, 115, 1804.

3 W. Wernsdorfer, N. Aliaga-Alcalde, D. N. Hendrickson and G. Christou, Nature, 2002, 416, 406.

4 M. Mannini, F. Pineider, P. Sainctavit, C. Danieli, E. Otero, C. Sciancalepore, A. M. Talarico, M.-A. Arrio, A. Cornia, D. Gatteschi and R. Sessoli, Adv. Mater., 2008, $20,1$.

5 D. Gatteschi, A. Cornia, M. Mannini and R. Sessoli, Inorg. Chem., 2009, 48, 3408.

6 V. Corradini, R. Biagi, U. del Pennino, V. De Renzi, A. Gambardella, M. Affronte, C. A. Muryn, G. A. Timco and R. E. P. Winpenny, Inorg. Chem., 2007, 46, 4937.

7 E. Coronado, A. Forment-Aliaga, F. M. Romero, V. Corradini, R. Biagi, V. De Renzi, A. Gambardella and U. del Pennino, Inorg. Chem., 2005, 44, 7693.
8 A. Ghirri, V. Corradini, C. Cervetti, A. Candini, U. del Pennino, G. Timco, R. J. Pritchard, C. A. Muryn, R. E. P. Winpenny and M. Affronte, Adv. Funct. Mater., 2010, 20, 1.

9 F. Moro, V. Corradini, M. Evangelisti, V. De Renzi, R. Biagi, U. del Pennino, C. J. Milios, L. F. Jones and E. K. Brechin, J. Phys. Chem. B, 2008, 112, 9729.

10 M. Mannini, F. Pineider, C. Danieli, F. Totti, L. Soracel, Ph. Sainctavit, M.-A. Arrio, E. Otero, L. Joly, J. C. Cezar, A. Cornia and R. Sessoli, Nature, 2010, 468, 417.

11 V. Corradini, F. Moro, R. Biagi, V. De Renzi, U. del Pennino, S. Carretta, P. Santini, V. A. Milway, G. Timco, R. E. P. Winpenny and M. Affronte, Phys. Rev. B: Condens. Matter, 2009, 79, 144419 and selected for the April 27, 2009 issue of Virtual Journal of Nanoscale Science \& Technology.

12 V. Corradini, A. Ghirri, U. del Pennino, R. Biagi, V. A. Milway, G. Timco, F. Tuna, R. E. P. Winpenny and M. Affronte, Dalton Trans., 2010, 39, 4928.

13 F. Moro, V. Corradini, M. Evangelisti, R. Biagi, V. De Renzi, U. del Pennino, J. C. Cezar, R. Inglis, C. J. Milios and E. K. Brechin, Nanoscale, 2010, 2, 2698.

14 L. Bogani, L. Cavigli, M. Gurioli, R. L. Novak, M. Mannini, A. Caneschi, F. Pineider, R. Sessoli, M. Clemente-León, E. Coronado, A. Cornia and D. Gatteschi, Adv. Mater., 2007, 19, 3906.

15 M. Mannini, P. Sainctavit, R. Sessoli, C. Cartier dit Moulin, F. Pineider, M.-A. Arrio, A. Cornia and D. Gatteschi, Chem.-Eur. J., 2008, 14, 7530.

16 J. B. Fenn, M. Mann, C. K. Meng, F. S. Wong and C. M. Whitehouse, Science, 1989, 64, 4926.

17 I. Uematsu, H. Matsumoto, K. Morota, M. Minagawa, A. Tanioka, Y. Yamagata and K. Inoue, J. Colloid Interface Sci., 2004, 269, 336; V. N. Morozov and T. Ya. Morozova, Anal. Chem., 1999, 71, 3110.

18 V. N. Morozov, A. V. Gavryushkin and A. A. Deev, J. Biochem. Biophys. Methods, 2002, 51, 57.

19 B. Hoyer, G. Sorensen, N. Jensen, D. B. Nielsen and B. Larsen, Anal. Chem., 1996, 68, 3840.

20 J. C. Swarbrick, J. B. Taylor and J. N. O'Shea, Appl. Surf. Sci., 2006, 252, 5622.

21 K. J. Kitching, H.-N. Lee, W. T. Elam, E. E. Johnston, H. MacGregor, R. J. Miller, F. Turecek and B. D. Ratner, Rev. Sci. Instrum., 2003, 74, 4832.

22 S. Rauschenbach, F. L. Stadler, E. Lunedei, N. Malinowski, S. Koltsov, G. Costantini and K. Kern, Small, 2006, 4, 540.

23 Q. Hu, P. Wang, P. L. Gassman and J. Laskin, Anal. Chem., 2009, 81, 7302 .

24 J. Alvarez, J. H. Futrell and J. Laskin, J. Phys. Chem. A, 2006, 110, 1678.

25 S. Rauschenbach, R. Vogelgesang, N. Malinowski, J. W. Gerlach, M. Benyoucef, G. Costantini, Z. Deng, N. Thontasen and K. Kern, ACS Nano, 2009, 3, 2901.

26 N. Thontasen, G. Levita, N. Malinowski, Z. Deng, S. Rauschenbach and K. Kern, J. Phys. Chem. C, 2010, 114, 17768.

27 S. A. Miller, H. Luo, S. J. Pachuta and R. G. Cooks, Science, 1997, $275,1447$.

28 Z. Ouyang, Z. Takats, T. A. Blake, B. Gologan, A. J. Guymon, J. M. Wiseman, J. C. Oliver, V. J. Davisson and R. G. Cooks, Science, 2003, 301, 1351.

29 B. Gologan, J. R. Green, J. Alvarez, J. Laskin and R. G. Cooks, Phys. Chem. Chem. Phys., 2005, 7, 1490.

30 R. Moroni, R. Buzio, A. Chincarini, U. Valbusa, F. Buatier de Mongeot, L. Bogani, A. Caneschi, R. Sessoli, L. Cavigli and M. Gurioli, J. Mater. Chem., 2008, 18, 109.

31 A. Saywell, G. Magnano, C. J. Satterley, L. M. A. Perdigão, A. J. Britton, N. Taleb, M. del C. Giménez-López, N. R. Champness, J. N. O'Shea and P. H. Beton, Nat. Commun., 2010, 1, 75.

32 M. Affronte, et al., J. Phys. D: Appl. Phys., 2007, 40, 2999; F. Troiani, et al., Phys. Rev. Lett., 2005, 94, 190501.

33 G. A. Timco, S. Carretta, F. Troiani, F. Tuna, R. J. Pritchard, C. A. Muryn, E. J. L. McInnes, A. Ghirri, A. Candini, P. Santini, G. Amoretti, M. Affronte and R. E. P. Winpenny, Nat. Nanotechnol., $2009,4,173$

34 A. Candini, G. Lorusso, F. Troiani, A. Ghirri, S. Carretta, P. Santini, G. Amoretti, C. Muryn, F. Tuna, G. Timco, E. J. L. McInnes, R. E. P. Winpenny, W. Wernsdorfer and M. Affronte, Phys. Rev. Lett., 2010, 104, 037203. 
35 R. D. Cannon and R. P. White, Prog. Inorg. Chem., 1988, 36, 195.

36 I. Rousochatzakis, et al., Phys. Rev. Lett., 2005, 94, 147204; T. Yamase, et al., Inorg. Chem., 2004, 43, 8150.

37 K. Y. Choi, Y. H. Matsuda, H. Nojiri, U. Kortz, F. Hussain, A. C. Stowe, C. Ramsey and N. S. Dalal, Phys. Rev. Lett., 2006, 96, 107202 .

38 S. Carretta, P. Santini, G. Amoretti, F. Troiani and M. Affronte, Phys. Rev. B: Condens. Matter, 2007, 76, 024408.

39 M. Trif, F. Troiani, D. Stepanenko and D. Loss, Phys. Rev. Lett., 2008, 101, 217201.

40 G. Lorusso, V. Corradini, A. Candini, A. Ghirri, R. Biagi, U. del Pennino, S. Carretta, E. Garlatti, P. Santini, G. Amoretti, G. Timco, R. E. P. Winpenny and M. Affronte, Phys. Rev. B: Condens. Matter, 2010, 82, 144420.

41 A. S. Batsanov, G. A. Timko, Yu. T. Struchkov, N. V. Gerbeleu and O. S. Manole, Koord. Khim., 1991, 17, 922; A. S. Batsanov,
Yu. T. Struchkov, N. V. Gerbeleu, G. A. Timko and O. S. Manole, Koord. Khim., 1994, 20, 833.

42 P. Kebarle and M. Peschke, Anal. Chim. Acta, 2000, 406, 11.

43 J. F. de la Mora, Anal. Chim. Acta, 2000, 406, 93.

44 S. P. Palii, D. E. Richardson, M. L. Hansen, B. B. Iversen, F. K. Larsen, L. Singerean, G. A. Timco, N. V. Gerbeleu, K. R. Jennings and J. R. Eyler, Inorg. Chim. Acta, 2001, 319, 23.

45 B. Gologan, Z. Takats, J. Alvarez, J. Wiseman, N. Talaty, Z. Ouyang and R. G. Cooks, J. Am. Soc. Mass Spectrom., 2004, 15, 1874.

46 D. G. Castner, K. Hinds and D. W. Grainger, Langmuir, 1996, 12, 5083 .

47 T. Ishida, N. Choi, W. Mizutani, H. Tokumoto, I. Kojima, H. Azehara, H. Hokari, U. Akiba and M. Fujihira, Langmuir, 1999, 15, 6799; T. Ishida, M. Hara, I. Kojima, S. Tsuneda, N. Nishida, H. Sasabe and W. Knoll, Langmuir, 1998, 14, 2092. 